\title{
Inoculation of oil palm seedlings in Malaysia with white-rot hymenomycetes: assessment of pathogenicity and vegetative growth
}

\begin{abstract}
The pathogenicity of white-rot hymenomycetes isolated from oil palm (Elaeis guineensis Jacq.) trunks and their effect on the vegetative growth of oil palm seedlings were investigated under nursery condition. The hymenomycetes were selected based on their potential antagonistic ability against the pathogen Ganoderma boninense from a previous study. Rubber wood blocks (RWB's) pre-colonized with either one of the seven hymenomycetes or the pathogen G. boninense PER 71 were placed in direct contact with the roots of threemonth-old oil palm seedlings using a sitting technique. After nine months, the seedlings inoculated with G. boninense were severely infected and the infection had spread throughout the seedlings, causing basal stem rot. By contrast, the fronds and boles of the seedlings inoculated with each of the seven hymenomycetes were symptomless until the end of the 18months study. The frond length of seedlings inoculated with Trametes lactinea FBW or Clitopilus prunulus ST3 was about 2.7-fold greater than those of seedlings inoculated with G. boninense PER 71. Similarly, after nine months, the chlorophyll content of seedlings inoculated with Lentinus tigrinus FBJ G3 or Pycnoporus sanguineus FBR was approximately 60 or 59 SPAD units, respectively, which was significantly higher than that of seedlings inoculated with G. boninense PER 71. The seedlings inoculated with each of the seven hymenomycetes showed a similar growth pattern in terms of frond count, plant girth, plant height and frond length, at nine months. These findings suggested the non-pathogenic nature of the selected seven white-rot hymenomycetes on oil palm seedlings and their possible use as biological control agents against the BSR pathogen, G. boninense. The findings should be further explored for their biocontrol potential under natural field conditions.
\end{abstract}

Keyword: Ganoderma boninense; Basal stem rot; Disease development; Hymenomycetes; Pathogenicity; Oil palm 